\title{
DECONSTRUCCIÓN DEL REALISMO. PARADOJAS DE LA METÁFORA DEL TEATRO EN EL VANO AYER DE ISAAC ROSA
}

AnNe-LAure Rebreyend Casa de Velázquez / Université Bordeaux Montaigne

Nos proponemos estudiar un relato que piensa y deconstruye los modos realistas de la novela de la memoria en España, a partir del análisis de la metáfora del espectáculo teatral proteiforme y omnipresente en la obra El vano ayer de Isaac Rosa (2004), y emprendiendo un diálogo con el artículo de Geneviève Champeau (2014)1. Esta novela nos interesa por varios motivos. Consiguió un notorio éxito entre los lectores y los críticos: fue Premio Ojo Crítico en 2004, Premio Andalucía de la Crítica, Premio Rómulo Gallegos en 2005, lo que significa que respondió a una demanda social y que se le otorga cierta ejemplaridad en el país. Además, en las tipologías que proponen los estudiosos, aparece en un principio como representante de una literatura de alto nivel, que no caería en las trampas fáciles de la mercancía cultural. Veamos en qué medida puede cobrar, pues, este valor específico de modelo dentro de cierto paradigma crítico. Este valor desempeñará probablemente un papel importante dentro de la configuración de la categoría crítica de los "nuevos realismos". Lo importante, a la hora de analizar una obra que ya de por sí es tan reflexiva y metaficcional, estribará en practicar conjuntamente dos operaciones. Por una parte, examinar

\footnotetext{
1 Una primera parte de este trabajo, bastante distinta de esta versión, la presenté en Burdeos el 10 de mayo de 2012 durante la Jornada Metáforas y vínculo social organizada por la UFI Historia, Pensamiento y Cultura Material, Europa y el Mundo Atlántico (Universidad del País VascoUniversité Bordeaux Montaigne). Se titulaba entonces "Memoria y sociedad del espectáculo. Bazas y paradojas de la metáfora teatral en Isaac Rosa".
} 
el funcionamiento complejo, y hasta subliminal, de los dispositivos del texto que sostienen los propósitos explícitos de la instancia de narración. Veremos que la metáfora del teatro es una de las más empleadas y más eficaces. Por otra parte, poner en perspectiva sus postulados con el contexto cultural e ideológico en el que acaece, tanto más cuanto que esta obra no llega sola sino tras más de diez años de intensa publicación en la literatura de la memoria, frente a la cual se posiciona claramente.

¿Qué entendemos aquí por metáfora teatral? Se atenderá al procedimiento de transposición de predicados que se refieren a la materia de la memoria (el contexto político del franquismo a la vez que a su representación literaria realista tópica), hacia otros que remiten al campo del teatro, de las múltiples modalidades del espectáculo. Nos interesa tanto la dinámica de estas transposiciones en el texto como el sentido y el valor (ético, ideológico) de la tensión, del conflicto estético y ético entre los términos que constituyen el enunciado metafórico. También destacaremos puntualmente dispositivos enunciativos con valor metafórico, como lo hace Geneviève Champeau (2014) a propósito de la puesta en escena de los trabajadores en La mano invisible.

Trataremos de explorar la categoría crítica de los "nuevos realismos" - usada a menudo para designar las modalidades actuales del relato realistadesplegando los múltiples sentidos que adquiere la metáfora teatral en la obra. Esta vincula el realismo actual con la escritura de la memoria, avatar del pensamiento de la Historia consubstancial al realismo desde el siglo XIX, reclama y emprende una renovación de la concepción de la representación, de la mímesis, y dibuja una relación problemática con la genealogía realista heredada de la historia de la literatura española. La metáfora del teatro, en su modalidad degradada de la farsa, plasma los fallos del discurso realista actual para contar el pasado. En su versión más reflexiva, brechtiana, busca exhibir la construcción que preside al discurso, los imaginarios sociales, la ficción. Las perspectivas arrojadas por la obra sobre un debate cardinal del realismo artístico, el de la fábula y la representación, pueden brindarnos ciertas claves para entender en qué consiste "la novedad" del realismo literario contemporáneo en España.

1. Difusión de la metáfora del teatro. Renovar críticamente la novela de la MEMORIA

El vano ayer es una novela mordaz y metanarrativa, que parece plantearse el doble objetivo de criticar el corpus de la novela de la memoria y de proponer su propio planteamiento del pasado reciente español. No es fácil identificarla como novela, de tan maltratados como resultan los ingredientes del género. Los protagonistas apenas merecen este estatuto, la diégesis está fragmentada, la inmersión ficcional se ve dificultada por las constantes intervenciones de la instancia narrativa, que en este relato es también el autor del libro que el narratario tiene entre las manos. El relato parte de las investigaciones bibliográficas del escritor diegético, que selecciona un nombre evocado a pie de página en una obra historiográfica: Julio Denis. Es este un universitario ya mayor al que por mo- 
tivos desconocidos expulsan de su cátedra en los años 1960, en plena revuelta estudiantil contra el franquismo, y que acaba desapareciendo. A lo largo del relato se encadenan capítulos que contrastan diferentes documentos o testimonios (nunca determinados claramente como factuales o ficticios), que plantean varias hipótesis respecto de la biografía y del posible compromiso político del profesor. Ceden el paso paulatinamente a la evocación de la militancia de un grupo de estudiantes y de la represión con la que se tienen que enfrentar. Esta trama alterna está entrecortada por las reflexiones metanarrativas del autor diegético: analiza superlativamente los mecanismos de la ficción, tanto la que está elaborando y cuyas estrategias narrativas va desmenuzando, como las de una corriente hegemónica de la literatura de la memoria, apuntando hacia sus escollos.

Varios análisis críticos han especificado ya los enfoques, objetivos y motivos de la crítica emprendida por el relato (Sanz Villanueva 2009, Bonvallot 2010, Labrador 2010 y 2011, Carcelen 2011, Florenchie 2011). Sin embargo, creo que queda por destacar y analizar la función estructurante y el funcionamiento paradójico de la metáfora de la teatralidad en la obra. Tal metáfora sirve primero, en las modalidades "grotesca" y "patética" propuestas por Geneviève Champeau (2014), para designar los géneros de la memoria contra los que escribe el autor (diegético así como real). Fustiga la distorsión maniquea, sensacionalista y atemporal que imprimen a la realidad de la que se hacen cargo. ¿A qué se debe aquella nocividad? Seguiremos a lo largo del texto la pista, en sentido literal y espacial, de las múltiples ocurrencias de la metáfora; la red que se dibujará pone en evidencia cómo aquella imagen deformada del pasado sigue vigente desde el franquismo hasta hoy impregnando los discursos contemporáneos.

La exigencia y el desafío que implica El vano ayer consisten en no tender la trampa de la comedia para representar el pasado reciente de España, al contrario de lo que la instancia narrativa denuncia como rasgo característico de la ficción de memoria histórica. Es lo que destacan obsesivamente los comentarios metanarrativos. Remiten casi sistemáticamente a la metáfora o a la comparación con el género teatral (que permite abarcar tanto la novela como las series televisivas, el cine o el cómic, asociados con las tonalidades grotesca o patética). Nos centraremos sobre todo en aquella, mucho más presente:

... el lector inquieto se desentiende con fastidio ante la enésima variación [...] de un tema viejo, como una cansina representación de esa commedia dell'arte en que hemos convertido nuestro último siglo de historia, en la que los verdugos apenas asustan con sus antifaces bufonescos, inofensivos Polichinelas que mueven a la compasión, o, por el contrario, crueles Matamoros... (Rosa 2004: 21)

Entramos de lleno en la relación dialógica del texto con los otros discursos sobre la realidad subrayada por Geneviève Champeau (2014) o por Philippe Dufour (1998): "La obra realista pone en tela de juicio la representación que se da de la realidad [...]. El realismo no representa lo real sino el discurso sobre lo real" (Dufour 1998: 90-91). Aquí el diálogo explícito se hace con algunos de los corpus de máxima producción y mayor número de ventas en España, éxito que motiva 
la escritura y que hace inevitable e imprescindible la intertextualidad, como lo declara el propio Rosa:

La forma puede establecer una continuidad, un diálogo o una ruptura con la literatura que enmarca tu obra. Se ve claro cuando uno decide escribir sobre la Guerra Civil, un tema tan escrito: la opción formal no es inocente, [...] se hace con/desde/contra/hacia toda la literatura precedente y contemporánea sobre el asunto. (Martínez Rubio 2013: 263)

Respecto a las deficiencias de esta oleada de "novelas de la memoria", el autor diegético y extradiegético se confunden, o sea que las tomas de posición dentro de El Vano ayer y en el epitexto coinciden para identificar lo que podríamos sintetizar como tres fallos. Están estrechamente vinculados, pero los distinguiremos en nuestro estudio para mayor claridad.

Primero, la atemporalidad del tratamiento de la Guerra Civil y del franquismo. La metáfora teatral, encadenada a lo largo de los discursos metanarrativos, opera señalando el carácter artificial de la escenificación. Convoca ampliamente las múltiples modalidades del espectáculo para el sistema espacio-temporal, el tema ("cuanto de novelable hay en esos años, [...] mero escenario para ambientar pasiones", Rosa 2004: 250) o los personajes ("los villanos, que como los héroes se burlan del autor y se enrocan en caracteres sin aristas, como marionetas del bien o del mal", 38). Lo que se denuncia es que se relegan los acontecimientos del pasado reciente a un tiempo ahistórico, mítico, que causa nostalgia, sentimentalismo, maniqueísmo acrítico. El pasado resulta despojado de su componente conflictivo ("el mal como defecto innato, ajeno a dinámicas históricas o intereses económicos", 22) o de sus estrechos vínculos con el presente. La crítica enunciada por Rosa se integra en una red de discursos de estudiosos con los que comparte valores y reivindicaciones de una izquierda crítica. Denuncian un relato hegemónico que naturaliza el pasado. Asimismo Catherine Orsini remite a las palabras de Jo Labanyi (2007) y afirma que gran parte de las novelas de la memoria puede "reforzar la diferencia entre presente y pasado de modo que, al acabar la lectura, el lector experimenta alivio al reanudar con un tiempo libre de tal barbarie" (Orsini 2010: 55). Esta reivindicación, compartida también por los historiadores Jesús Izquierdo Martín y Pablo Sánchez León (2006) o François Godicheau, los críticos José Colmeiro (2005), Constantino Bértolo (2007a y 2007b), Matías Escalera Cordero (2007), Anne-Laure Bonvalot (2010) o los escritores Marta Sanz (2001) o Belén Gopegui (2008), la repite tenazmente Isaac Rosa en varias entrevistas (Corominas 2007 y Riaño 2011b) y presentaciones públicas.

De hecho, el segundo fallo de la ficción de la memoria histórica que se identifica en El vano ayer por medio de la teatralidad es que tal atemporalidad crítica y nostálgica es heredera de la visión franquista (épica) de la historia. El relato lo pone de relieve mediante un juego de reapropiación paródica de las pautas discursivas (en el sentido de Víctor Klemperer) del franquismo. De este modo, subraya la circulación de sus registros hasta el día de hoy. Destaquemos en la novela ejemplos elocuentes del uso común de la metáfora del espectáculo tanto en la descripción de la realidad por el franquismo como en la represen- 
tación del franquismo por la ficción contemporánea. Un mismo recurso teatral enfatiza un vínculo ideológico que vuelve inofensivo, por bufonesco, el pasado.

La metáfora del espectáculo en todo su espectro funciona como una red de sentido por ecos. Ya hemos visto que servía en un primer nivel para designar la ficción de la memoria histórica. En un segundo nivel, opera interpretando, recalificando el discurso franquista cuando este emplea un vocabulario técnico y eufemístico para aludir a la represión. La instancia narradora despliega e imita la retórica franquista en la novela. Se insertan notas de prensa del régimen ficticias, que insisten en el benéfico mantenimiento del orden público ("Incidentes en la Facultad de filosofía y letras", Rosa 2004: 82 y 83) y el desarrollo ejemplar de un juicio a un preso político ("Grimau, plenamente restablecido", 134-136); o declaraciones de un policía que propone arrojar una luz verídica sobre irreprochables prácticas represivas (265-290). Pero a estas mímesis formales de relatos franquistas responden intervenciones de la voz narradora que, al evidenciar la inverosimilitud del relato franquista, desmontan su retórica. Por ejemplo, reclama la memoria de

otros jóvenes, pocos recordados, muchos olvidados, que ya perdieron sus nombres y que fueron capaces de prodigios enviados por Houdini: ahorcarse con las manos esposadas, bucear pantanos con el cráneo astillado a balazos, detener a voluntad la respiración y los latidos del corazón (parada cardiorrespiratoria lo llamaban...). (Rosa 2004: 38-39)

El mundo de la magia y del circo toma de nuevo el relevo para subrayar las trampas discursivas de la retórica. Luego, en un tercer nivel, se difunde esta visión desrealizadora y este campo léxico en el tejido del relato: la sutileza y eficacia radica en que aparecen incluso en boca de protagonistas no franquistas. Es el caso del catedrático jubilado Emilio de Lorenzo, identificado como amigo de Julio Denis y no favorable al franquismo. De ese modo acaba su recuerdo de la represión policial de una huelga universitaria: "los policías [...] se lanzaban a perseguir porra en mano a los estudiantes, en una competición de patinadores que tenía mucho de circense"(37). La gratuidad estética de la coreografía es el eufemismo que se integra fluidamente en el discurso, dulcificando sin que lo advirtamos la violencia de la represión. Este procedimiento subraya sutilmente la eficaz e invisible infiltración de la visión propia del bando de la dictadura hacia la oposición o incluso el marco del "sentido común"2.

Este tránsito de una ideología por las pautas del lenguaje se ve redoblado por su implantación como género (teatral, circense) y como registro (cómico y grotesco) en la ficción. Aparece contundentemente en un capítulo central de la novela (149-154) que cuenta la irrupción de la policía en medio de una reunión del grupo de estudiantes militantes que llevamos siguiendo a lo largo de varios

\footnotetext{
2 Queremos destacar otro ejemplo del mismo procedimiento de circulación de expresiones. El eufemismo "se pudo ir un poco de la mano", empleado por un policía del régimen (entre muchos otros como "forzar un poco la voluntad del detenido" o "se hace necesaria cierta dureza", Rosa 2004: 272-273), lo emplean también dos antiguos opositores estudiantiles al franquismo: "se les fue la mano" (41), "se fue de las manos" (66).
} 
capítulos. El recurso empleado es el motivo de la risa y la metáfora encadenada del espectáculo en todas las modalidades que hemos destacado. Seleccionamos aquí algunos de los fragmentos significativos de la continua yuxtaposición que constituye el relato:

André [y sus compañeros] [...] se abrazaron como bufones haciendo las bromas esperadas, uno tomaba la pierna del otro [...], este se colocaba a cuatro patas tras el burlado para que otro lo empujase y cayese con pataleo [...] hasta que los agentes de paisano irrumpieron por la puerta con espectacularidad de payasos, empuñando pistolas de agua [...], María [...] pasó varias horas en un despacho con varios policías [...] y entonces hicieron el simulacro circense de la bofetada, un policía simulaba que le daba un cachete y ella daba palmas con las manos en la espalda imitando el sonido de la bofetada [...], era un número muy efectista [...], André había desaparecido como en un número de magia ambulante, ese era otro de los trucos favoritos que se hacían en Sol... (Rosa 2004: 149-154)

Se teje aquí la áspera parodia de un tratamiento ficcional que, por desfasado, se aleja de una realidad brutal, revelada oblicuamente, entre líneas. Según Labrador, se trata de enfatizar un problema de decoro, o sea "la fractura entre tono y contenido, entre estilo y referente" (2011: 123). Este planteamiento central del decoro nos llevará a la cuestión del género en la literatura de la memoria, sobre el que volveremos más adelante. Ya podemos adelantar sin embargo que, muy sencilla pero claramente, viene evidenciado de manera plástica por el uso continuo de una metáfora que remite precisamente a otro género, el del teatro.

Hemos recalcado una red de circulación de la metáfora entre una multiplicidad de enunciadores de diversas adscripciones políticas. Esta red funcionaría como demostración estética que pudiera, si no conjurar la pervivencia de esquemas representativos franquistas en los imaginarios sociales, al menos contribuir a una toma de conciencia de esta. Para completar dicho procedimiento de la novela, mencionemos una vuelta de tuerca suplementaria del aparato metafórico. Se trata de la representación de la agresión física y verbal que sufre Julio Denis en un anfiteatro, cuando un grupo de militantes sospecha que ha delatado a su compañero André Sánchez. Todo el relato lo cuenta un antiguo estudiante (Rosa 2004: 45-51), que no reivindica ningún bando político ni simpatiza con la causa militante:

... aquella agresión fue el broche final de una aplaudida representación tragicómica de la que el profesor fue protagonista y víctima. La mise en scène fue brillante [...], parecía que sus ejecutores la hubieran ensayado a fondo para afinar cada entrada, [...] cada gesto afectado hasta la coda genial en forma de [...] lanzamiento de bolígrafo al profesor, quien había asistido a la obra como un actor senil que no recuerda su párrafo y desoye al apuntador. (Rosa 2004: 46)

Los organizadores iniciaron su teatrillo [...] un segundo alumno [...] que también formaba parte del reparto en aquella comedia, repitió desde el extremo opuesto del aula: por qué no habla de André Sánchez. (Rosa 2004: 48) 
Ya estaba listo para saltar el siguiente resorte de la representación [...]; y para dar más dramatismo al momento y despertar el horror en los que todavía pudiéramos permanecer indecisos, el joven gritó... (Rosa 2004: 50)

Primero, la voz enunciadora de este pasaje estructura su relato del altercado según pautas de una coreografía teatral, para sugerir que los protagonistas orquestaron una estrategia de persuasión mediante recursos y efectos ("despertar el horror") propios del drama. Insiste además en nombrar al cabecilla de la operación según lo que parece ser un accesorio de la dramaturgia: un "alumno, ritualmente barbudo pese a su juventud" (Rosa 2004: 48), "el orador barbudo" o "el de la barba revolucionaria" (49). Este recurso sugiere una suerte de "mala fe" sartriana en la autoconvicción a la que llegarían los militantes por desempeñar hasta el exceso su propio papel. Su elocuente conclusión ("los demás estábamos demasiado incómodos con todo este teatro", 50) permite interpretar el insistente encadenamiento de la metáfora teatral como un procedimiento que introduce la sospecha del enunciador respecto a la legitimidad de la manifestación estudiantil. De este modo, la despolitiza: tercer fallo estético y ético de la ficción de la memoria.

Dicha despolitización del relato del pasado caracteriza el pacto consensual de la Transición, según Rosa en El vano ayer y en sus intervenciones públicas, y según estudiosos y artistas portadores de una voz crítica que se afirma en muchos niveles de la sociedad española, en el contexto actual de crisis política, económica y cultural. Identifican en todos los ámbitos de la vida pública un rechazo a los conflictos ideológicos, condición elaborada desde el régimen franquista para dar un paso hacia la democracia pactada con la derecha conservadora (Garcés 1993, Chamouleau 2011, Martínez 2012, VV.AA. 2013). A la lógica de la equiparación apolítica de las culpas (Rosa 2004: 249) y la exigencia de consenso (250), las tramas sentimentales de la ficción y el tratamiento inocuamente garbancero del franquismo (31), El vano ayer responde debilitándolos y parodiándolos a través de varios procedimientos. Emplea la imagen de la farsa, ironiza sobre el recurso polifónico que emplea (81), reivindica el protagonismo antifranquista del PCE (58), elige temas a los que devuelve su valor subversivo: las prácticas cotidianas de represión, la tortura (en dos capítulos centrales del libro, 113-130 y 155-170), la corrupción y la impunidad de los obreros de la dictadura (delatores, jueces, empresarios, 78, 79, 162, 195-208). A la elección masiva del tiempo más lejano de la Guerra Civil y de la posguerra en la ficción, Rosa prefiere el tiempo del tardofranquismo y de la Transición, con ineludible precisión de fechas, continuidades y remanencias en el tiempo presente $(94,152,153)$. Hemos analizado cómo las plasma en el texto mediante la red de representaciones mentales y verbales que la metáfora de la teatralidad abandera y trasciende.

A raíz de esta primera etapa del análisis, ¿en qué sentidos correspondería El vano ayer a la tendencia que se suele identificar como "nuevos realismos"? Una respuesta podría estribar en que el relato se suma a esta literatura y esta demanda social que, desde los años 80 pero sobre todo 1990 y 2000, identifica un vacío de conocimiento y de memoria por parte de las instituciones con respecto al pasado reciente. Pero Rosa va más allá y se distingue apuntando hacia partes 
de ese pasado que, además de su silenciamiento político, siguen siendo el punto ciego de este nuevo discurso ficcional. Enfrentarse al mundo del trabajo en $L a$ mano invisible radicaría en el mismo proceso. En este sentido resulta "nuevo". Sin embargo, también resulta críticamente nuevo, nuevo por contraposición, pues su propuesta estética se apoya en la crítica de los realismos que le son contemporáneos. Y, a este respecto, no se trata tanto de colmar un vacío como de poner de realce unos procedimientos generalizados para deconstruirlos. La metáfora del teatro, en las múltiples modalidades que hemos tratado de evidenciar, se hace cargo de estos aspectos.

Tales elecciones narrativas destacan por su coherencia, eficacia y reflexiva lucidez, por la fuerza política que cobra la conjunción de los dispositivos y de la selección de referentes del relato. Ahora bien, se llevan a cabo en nombre de la responsabilidad inherente a cualquier artefacto artístico a la hora de asumir la representación de la realidad, tanto más cuanto que el relato trata de contribuir a la construcción de la memoria.

\section{TRAMPAS DE LA METÁFORA Y PARADOJAS DE LA MímESIS REALISTA}

La obra, de nuevo por la metáfora de la teatralidad, plantea que el pernicioso alcance de estos rasgos generalizados estriba en que descansan en un poder performativo de la ficción de la memoria histórica en el imaginario colectivo. De ahí que Rosa cuestione, con un recurso próximo a la teatralidad "reflexiva" de La mano invisible, aunque de manera más implícita, la propia posibilidad de la representación literaria y política. Este paso lo hará por un gran gesto crítico que unifica, asimila, varios subgéneros del régimen de representación realista en la historia literaria. Lo desarrolla mediante un uso aglomerante y omnipotente de la metáfora teatral que cabe cuestionar. Vamos a ver que funciona ante todo como gesto fundador de una renovación de la mímesis. Apunta Roger Chartier que las representaciones estéticas

no representan directamente una realidad ya presente y constituida, sino que contribuyen a su producción, y, quizás, más fuertemente que otras representaciones desprovistas del poder de la ficción. [...] Si es verdadero que las obras estéticas no son jamás meros documentos del pasado, es también verdadero que a su modo, entre veras y burlas, ellas organizan las experiencias compartidas o singulares que construyen lo que podemos considerar como lo real. (Chartier 2002: 14-15)

La valoración de Rosa como escritor "responsable", que no duda en comprometerse, arranca justamente de la conciencia de esta performatividad de la ficción en el imaginario social, como lo resaltan sus entrevistas. Es una reflexión que viene siendo hoy la de gran parte del campo de la historiografía y de las ciencias sociales. De ahí que El vano ayer "habl[e] de cómo una sociedad se enfrenta a un pasado conflictivo, cómo lo gestiona, metaboliza e incorpora al presente, y qué ocurre con la transmisión de esa memoria a las nuevas generaciones" (Martínez Rubio 2013: 264). Es, pues, una cuestión de representación política a la vez 
que literaria; de ahí que importen tanto el lugar de enunciación de los relatos como sus dinámicas de apropiación, que pasamos a analizar.

Ya hemos mencionado que una operación muy importante de El vano ayer es asimilar el régimen franquista y la cultura de la Transición, en lo que hereda de este, como una fuente matricial de configuración de la relación con el pasado reciente en España. "Ya está bien de repetir la versión de los vencedores" (Rosa 2004: 249), resuelve la instancia narradora. Pero la cuestión de la legitimidad y de la representatividad del relato abarca también, dentro del mismo bando de la oposición, el conflicto de las memorias y, por consiguiente, del poder discursivo, en el sentido de Rancière (2000). Al final del capítulo clave de la obra que acomete la representación de la tortura, la víctima que confiesa rechaza amargamente

la típica basura heroica, toda esa retórica de los héroes, [...] el bonito relato de esos intelectuales que rara vez sufrían torturas [...] dedicaban el tiempo de prisión [...] a formarse, a las lecturas [...], los trataban con corrección para que no protestasen, porque [...] podían convocar campañas de apoyo [...] para luego, ya en la democracia, poder decir bien alto que ellos eran la verdadera oposición a Franco. (Rosa 2004: 170-171)

Hay una desigualdad en las posibilidades de enunciación desde el punto de vista del testimonio, una escala de legitimidad discursiva que resulta determinante para la memoria (aquí la de la oposición). La alternancia de voces organizada por el relato y la focalización interna sobre varios testigos enlazan así el lugar de enunciación literaria con la representación política. Notemos con Geneviève Champeau (2014) que La mano invisible desarrolla un procedimiento similar con los obreros. Este vínculo podría señalar que si el diálogo con voces y subjetividades procedentes de la "gente cualquiera" es un desafío de la literatura de la memoria más reciente (Labrador 2012) ${ }^{4}$, en realidad manifiesta, de manera más general, el fenómeno del retorno de lo real en la literatura.

Ahora bien, dentro de los mismos testimonios en focalización interna (no nos detendremos aquí considerar su ficcionalidad o factualidad) que orquesta El vano ayer, especialmente en los relatos de tortura, los dispositivos formales plasman las dinámicas de intervención de los esquemas ficcionales en la elaboración y apropiación de los relatos. La metáfora del teatro enfatiza esta construcción de representaciones colectivas. Hemos analizado ya algunas estrate-

\footnotetext{
3 El mismo planteamiento aparece en La caída de Madrid, de Rafael Chirbes, cuando Taboada declara a Lucio, sobre la escritura de la Historia: "Eso es lo que quedará de vuestra lucha si no ganáis. Lo que no quede escrito, no habrá existido, y lo que ha existido lo escribirán ellos [los intelectuales]. [...] Tu pasado me lo inventaré yo a la medida de mis necesidades. [...] Esos años los escribiré yo, si sobrevivo y regreso a mi clase" (2000: 155). Gracias a Brice Chamouleau (2011) por haberlo advertido.

${ }^{4}$ Me baso en el manuscrito de la conferencia "Productos genéricos. Nuevos medios, géneros narrativos y ficción política en la España contemporánea", leída por Germán Labrador en el coloquio (Pen)insular Seminar. Sui generis. Ends and limits of literary genres (Departamento de Lenguas y Literaturas Románicas de la Universidad de Harvard) el 11 de mayo de 2012. La versión publicada de este trabajo es notablemente diferente (Labrador 2012). Le agradezco mucho a Germán Labrador que me facilitara la versión manuscrita.
} 
gias narrativas que dibujan el poder de infiltración del discurso franquista en los discursos del presente, es decir la persistencia de su retórica en los relatos. Más allá, la teatralidad que provendría de la configuración de la ficción aparece, además, como mediadora de los relatos de experiencia de los testigos, como matriz de conocimiento.

Es, por ejemplo, un esquema de novela o película policial el que determina el desarrollo ritual del interrogatorio franquista. Ya no se sabe si venía premeditado según este patrón o si las pautas, los clichés ficcionales preexisten a la percepción y la moldean. Un antiguo militante explica: "los dos agentes, que eran los típicos fantoches de la Social (uno mayor y otro joven, como reproduciendo el guion de esas comedias norteamericanas de la parejita policial, el veterano y el novato [...])" (Rosa 2004: 65); "Laurel y Hardy le explicaron que había una orden de detención..." (66); "Yo ya entendía que aquello no era un detalle del hotel, sino la típica escenografía para una paliza" (71). Las dos ocurrencias del adjetivo "típico" ${ }^{1}$ significan que se trata de acontecimientos y personajes recurrentes del pasado, lo que ya de por sí es una toma de posición fuerte, pues, según Rosa, es una realidad del régimen que se suele silenciar. Pero también remite a que los patrones ficcionales median tanto el testimonio como la vivencia misma; como si se viviera la experiencia según las ficciones preexistentes, que sirven de marco de entendimiento. Esto lo sugieren la comparación ("como") en tanto que operación cognitiva, y el nombrar a los policías según los famosos personajes cinematográficos, intermedialidad que enlaza con el bagaje cultural del narratario diegético y del propio lector, y crea una comunidad de sentido. El prisma de la ficción cinematográfica, redoblado a su vez por la modalidad teatral, crea sentido y respalda el conocimiento, condicionando, moldeando la vivencia y el testimonio enlazados, que luego se transmiten con las mismas metáforas. Por ende, la metáfora y la comparación despliegan un tercer nivel de sentido del adjetivo "típico". Se trata de la representación de esta clase de práctica dentro del tejido de relatos transmitidos en el seno de la clandestinidad. La transmisión estructura un mecanismo de anticipación del acontecimiento: "esta imaginación [...] hacía más terrible [la realidad], [...] aderezada por todos los relatos de maltrato policial que circulaban en la universidad y que impresionaban nuestro temor" (71); o "Me habían contado muchas historias de la Social, me habían referido toda una tipología de comisarios [...]: el violento, el frío, el que parece bueno..." (125). Por fin, esta multiplicidad de relatos testimoniales, más o menos ficticios, que alimenta la impresión y valoración de estas escenas como "típicas", es también la de los géneros de la memoria histórica a los que tiene acceso el lector.

La metáfora teatral se funde en estos fragmentos con el género cinematográfico remitiendo al reparto, a la kinésica (los movimientos y gestos de comunicación no verbal) y proxémica (relaciones espaciales entre los cuerpos) y al marco espacial. En el sentido propuesto, funciona como forma artística que evidencia su condición de artefacto. En una suerte de operación de distanciación

\footnotetext{
${ }^{5}$ Adjetivo que volveremos a encontrar en otro relato de tortura: "había poca luz, un solo flexo sobre la mesa, aquello tenía mucho de escenografía, de decorado de película norteamericana, solo faltaba el típico espejo que por un lado refleja y por otro deja ver" (Rosa 2004: 123).
} 
brechtiana (Sanz Villanueva 2009, Champeau 2014) deconstruye uno de los rasgos dialógicos de la elaboración del pasado mediante los patrones de la ficción, y toca la función cognitiva misma de la representación artística.

De hecho, al hilo de una de las fructíferas pistas exploradas por Germán Labrador (2011, 2012), formulamos la hipótesis de que El vano ayer, a partir de la deconstrucción de los géneros de literatura de la memoria, desentraña y cuestiona la posibilidad o la naturaleza de la mímesis. Es el debate clave del realismo si se lo define como una constante estética occidental. No sugerimos que la novela exacerbara una duda relativista respecto al poder referencial del lenguaje ni respecto a la existencia misma de una realidad. No es así como interpretamos el perspectivismo y la polifonía contradictoria en el relato. Los procedimientos que hemos advertido sí sugieren, sin embargo, la naturaleza discursiva de la realidad. El vano ayer se construye más bien según, con y contra la perspectiva de la ilusión referencial (Riffaterre 1982) que hace invisible el dispositivo narrativo para ostentar una relación casi inmediata con el referente hasta pretender o querer confundirse con él (Todorov 1982: 7 y 9). En este sentido, puede que, desde un punto de vista más metaliterario que patente y diegético, la teatralidad surja en tanto que reminiscencia crítica de los debates platónicos y aristotélicos que cotejaban relato y teatro en virtud de una jerarquización de la capacidad mimética según los géneros ${ }^{6}$.

En este sentido, el infratexto brechtiano, tanto por la distancia como por el gestus adoptados o adaptados por esta novela, remotivaría el hecho de recurrir a la teatralidad, masivamente empleado con valor de proscripción en El vano ayer. La mano invisible ahondará en la reflexión, citando además a Bertold Brecht en su peritexto (Rosa 2011: 381). El vano ayer explicita, pues, (una parte de) su construcción dialógica e intertextual, y la de cada una de sus relatos intradiegéticos para reparar en la doxa que sustenta la percepción de la verdad. Si "la descripción es verdadera porque se conforma a una mitología que el lector lleva en sí mismo, hecha de clichés y de tópicos" (Riffaterre 1970: 404), el peligro o el comportamiento narrativo indecoroso estriba en favorecer esta ilusión disimulando "al máximo la narración para que la ficción, en su ilusionista semejanza, pueda confundirse con esto de lo que pretende ser la imagen" (Ricardou 1970: $453)^{7}$. Así es como se discute en El vano ayer la posibilidad de la representación. La novela opera mediante la designación de un ejemplo a evitar, un enemigo literario; a saber, uno o varios géneros narrativos que tenderían descaradamente aquella trampa. El enemigo coincide con el objeto de las rotundas críticas de Brecht en el ámbito del teatro, o, en cuanto a la novela, de los escritores y críticos del Nouveau Roman francés, cuya influencia fue importante en la institución literaria española ya entre varios autores realistas desde los años 1950 (Champeau 1993: 278-298, 301). Se trata del realismo melodramático del que habla

\footnotetext{
6 La tipología aristotélica de los géneros literarios comparaba, como lo hacía Platón, el teatro y la narrativa según su grado de capacidad mimética, pero discrepaban los dos filósofos en cuanto al valor que daban a la mímesis. Como apuntan Gefen (2003: 28-29) y Compagnon (2001), las clasificaciones eran altamente prescriptivas y condicionaron toda la historia de la literatura.

7 Las traducciones al francés son mías.
} 
Labrador (2011: 126). La fuerza connotativa de la metáfora del teatro en El vano ayer estriba efectivamente en que los rasgos de la ficción de la memoria, tal y como aparecen denunciados y parodiados en esta novela, remiten a la estética melodramática, que proviene históricamente del teatro de finales del siglo XVIII y del siglo xIx (Ríos-Font 1997: 25-27). Cuadro previsible, argumento fundado en la tensión y las peripecias hasta un final triunfal, personajes-tipo, maniqueísmo y moralización, énfasis y espectacularidad, patetismo y sentimentalismo (Merino 2007: 57-60), constituyen los ingredientes del melodrama que cumplirían una función balsámica frente al derrumbamiento del orden social y las instituciones tradicionales desde la Revolución francesa hasta la actualidad. En un mismo gesto unificador, a expensas de matices y contextualización, la instancia enunciadora en El vano ayer los evidencia dentro de un amplio espectro de historia literaria. Las ficciones de la memoria se alimentarían, pues, de sus varios subgéneros. A continuación vamos a ver qué subgéneros viene uniendo la polivalente y omnipresente metáfora teatral dentro del relato.

Primero, el corpus de las "novelas de quiosco" que circulaba en los años del tardofranquismo (Rosa 2004: 30, 242). Segundo, las novelas policíacas (64, 172), cuyos mecanismos interioriza masivamente la novela española a partir de la Transición (Tyras 2011). La novela de la memoria tendría muchos procedimientos en común con estas producciones presentadas como paraliterarias. El principal radicaría en una función de entretenimiento vinculada con su estatuto de ficción. Así una novela de la memoria procuraría calcar "los usos de la novela contemporánea más exitosa (que debe ofrecer un mínimo de entretenimiento al lector)"(Rosas 2004: 212), y cualquier ambientación en la Guerra Civil asegura a los lectores que "estamos construyendo una ficción, señoras y señores, relájense" (220). Aquella literatura de diversión parece abarcar diferentes variantes de lo que se suele llamar la "renarrativización", por ejemplo, la vuelta de la anécdota y la intriga en nombre del placer de lectura, al entrar España en la sociedad de consumo desde la segunda mitad de los ochenta:

A esa novela "neonarrativa" pueden adscribirse otras variantes: la novela mítica y fantástica, la de acción, la histórica, la erótica; todas ellas dispuestas a conquistar a un público, no a ensanchar o ahondar horizontes nuevos en el arte de la novela. Luis Goytisolo ha llamado a buena parte de esta producción "novela neodecimonónica". (Sobejano 2003: 108)

Sucede que, lejos de considerar matices en el seno de las novelas que recurren al cuento, El vano ayer las hunde todas en una masa de prosa narrativa comercial. Nos lleva a un punto neurálgico para nuestro propósito: el vínculo entre la literatura de la memoria y los nuevos realismos funcionaría por la recuperación común de una relación complaciente con el público, heredada del realismo tradicional decimonónico y su estética próxima al folletín. Ahora bien, si prestamos mayor atención aún a la tipología de subgéneros que constituiría la

8 Consta de intrigas rocambolescas (Rosas 2004: 204), de espacios exóticos (206), humor, erotismo, argumento muy coherente (137), y responde a un criterio comercial (205). 
trama infratextual de la novela de la memoria según la instancia de enunciación de El vano ayer, comprobamos que la metáfora de la teatralidad goza, en la novela, de un problemático poder de amalgama:

... recuperé a André, convertidos en niños de la calle en aquella ciudad miserable de los años cincuenta (y aquí de nuevo pondremos dique al probable afluente que la narración nos abre, un relato según los patrones del realismo literario de entonces, con cabecitas rapadas, piojos, ropas remendadas... (Rosa 2004: 98-99; las cursivas son mías)

... el verdadero alarde se encuentra, en el fondo, en el contenido del relato, la tentación siempre presente de convertir al personaje en testigo y testimonio, utilizar su vida como coartada para relatar los fenomenales acontecimientos históricos de que fue contemporáneo, según el galdosiano modelo de los episodios nacionales. (Rosa 2004: 212-213; las cursivas son mías)

Comprobamos que en un mismo gesto de depreciación se vincularían, hasta se confundirían, el realismo decimonónico, el realismo social de mediados del siglo xx y la novela contemporánea, incluyendo la novela de quiosco, policial y de la memoria. ¿Qué distinciones borra esta operación? ¿Cuál es su sentido?

Cualquier historia de la literatura restablece las singularidades que distinguen estas corrientes entre ellas y que las agitan en su seno. Cada una de estas, en tanto que categoría de la crítica, atañe a polémicas y continuas aclaraciones. El realismo de los años 1950 no pertenece a un solo bloque (Champeau 1993); la obra literaria de Galdós conoce muchos cambios a lo largo de su trayectoria y sobre su componente melodramático se ha debatido con aspereza (véase la controversia entre Sobejano y Rubio en Anales Galdosianos, 1976). Incluso el tradicional maniqueísmo de la novela de la memoria ya no resulta tan de actualidad (Hansen 2011). Resulta imprescindible en este tema distinguir entre texto y epitexto, ya que las declaraciones de Rosa tienen en uno y otro un contenido diferente. La operación de equiparación, en El vano ayer, de esos variados epígonos del realismo se hace en virtud de un desentrañamiento del realismo en su vertiente melodramática. Además de su función de diversión, lo que vitupera el autor diegético se resume en la breve explicación que podemos proponer de estos fragmentos:

El padre de Denis tiene madera suficiente para el estereotipo caciquil, el industrial derechista duramente enfrentado a la conflictividad obrera de las primeras décadas del siglo: un hermoso retablo de las luchas socialistas en Sevilla... (Rosa 2004: 214)

Incluso [...] podemos aprovechar a don Denis padre para generar una de esas maravillosas historietas de rígida erudición, [...] toda esa exuberancia de valientes pilotos, máquinas soñadas, triunfos y tragedias que tanto enriquecería nuestra novela, material de fácil adquisición en cualquier crónica ilustrada de la aviación y que completaríamos con un discurso en torno a la tensión de progreso que rodea cualquier avance científico. (Rosa 2004: 215) 
El procedimiento que discute es la tipificación, ya sea en su variante folklórica o costumbrista entendida como exhibición artificial de un decorado seudo-referencial ("material de fácil adquisición en cualquier crónica ilustrada"), épico-heroica y, en última instancia, nacionalista. Hemos analizado anteriormente cómo el efecto de representación "típica" nacía de un efecto de circulación de sentidos: lo típico eran las pautas discursivas que se repetían en los relatos testimoniales o de la memoria. Llegamos ahora a una interrogación acerca del dispositivo de la "tipicidad" entendida como representación codificada por tipos de la condición de un personaje o de acontecimientos históricos (véanse las categorías señaladas por la singular pareja "el industrial derechista", "la conflictividad obrera"). El problema de la pobreza de medios literarios, sugerido en estos fragmentos a través de las enumeraciones yuxtapuestas de temas, que no pasan de meras "historietas" (o "zoología" y "anecdotarios de la vida cotidiana de nuestros ancestros", Rosa 2004: 214 y 213), estribaría en la intención del autor realista. Primero, este orquesta la referencialidad en función de una concepción ingenua de un lenguaje-copia que "pretend[e] reproducir un ambiente de época" (218), aunque "a fuerza de imitar la realidad acaba por hacerla increíble" (214; las cursivas son mías). Sin embargo, paradójica y simultáneamente, por una parte coordina la ilusión según una meta, una retórica de exaltación nacionalista y positivista hacia el progreso nacional ("la tensión de progreso", de la nación pero también la del texto mismo). Por otra parte, activa un esteticismo ("un hermoso retablo") que a fin de cuentas explota el tiempo pasado en nombre del arte. En otras palabras, moldea la realidad en función de los tópicos literarios y no al revés, como lo plasman la expresión y su preposición "tiene madera suficiente para", los verbos "aprovechar", "enriquecería", "completaríamos". ¿Cuál es el consiguiente problema literario? El autor persuade al lector de que contribuye al efecto de ilusión referencial; y se pasa del artificio del referente a la creencia en la verdad de lo referido. Rosa cita un caso, entre otros, en una entrevista:

Un ejemplo es La colmena de Cela. Sigue siendo leída como un documento de época, como la mejor imagen de la posguerra, y no es verdad, La colmena oculta mucho, no cuenta cómo era el Madrid de los años '40. Sin embargo, insisto, la novela es aceptada como un fiel reflejo. De hecho, Cela ha confesado que en $L a$ colmena él está escribiendo historia y la gente lo lee como tal. Muchos lectores tienen fijada la imagen de la posguerra por este libro. (Corominas 2007: s/p)

Formulamos la hipótesis de que es un enésimo avatar de la metáfora del espectáculo el que se hace cargo de romper esta identidad entre lenguaje literario y realidad referida. Se interponen las imágenes de la máscara y del disfraz (Rosa 2004: 18, 29, 53, 81, 218...) que forman plásticamente una pantalla entre los dos. La propia polivalencia polimorfa y omnipresente de la metáfora del espectáculo también podría ser una manera de crear una materia abundante que obstaculizara el acceso por vía directa a la realidad.

Resumamos. La metáfora teatral que analizamos reúne varios subgéneros del realismo literario. Los simplifica y critica por constituir el nexo impensado entre literatura de la memoria, realismo tradicional y nuevo realismo. No obs- 
tante, la clave del argumento reside a fin de cuentas en la dinámica de un pacto de lectura realista: se construye con una comunidad de lectores, que pueden actualizar la intención auctorial (Villanueva 1994). En otras palabras, si no tomamos el gesto de proscripción al pie de la letra, es preciso entender que sirve para reparar y hacer reparar en la pragmática del realismo, lo que sería la condición de su renovación. Lo vendría a confirmar la propuesta de tipología de unas "benditas novelas sobre la Guerra Civil" esbozada por Rosa en irónica intratextualidad durante una Jornada de estudios sobre Escrituras híbridas del pasado en Burdeos (9 de mayo de 2011). Propuso una lista de novelas y autores (Alfons Cervera, La voz dormida de Dulce Chacón, Martínez de Pisón, Almudena Grandes, Antonio Prometeo Moya, Dime quién soy de Julia Navarro...) que no necesariamente le agradaban ni convencían pero cuyo éxito de ventas les confería un valor de respuesta a una demanda social. Novelas que han cumplido de manera genuina una función de homenaje, de reivindicación, y que tuvieron una eficacia en términos de reparación literaria (matiz muy importante que no está presente en el libro).

Por último, en el texto, el poder de aglomeración y allanamiento de la mirada que equipara todas las novelas de la memoria a novelas de diversión es el mismo que el que confunde (en el sentido de fundir, valga la redundancia) muchas opciones realistas producidas desde el siglo xIx. Y sin embargo, el propio gesto de renovación por tabula rasa apunte tal vez a lo contrario: al problema de la genealogía en la que se sitúa.

Para esto, hace falta reparar en los ocasionales chirridos entre lo que dice la obra mediante las intervenciones metanarrativas y lo que esta lleva a cabo a través de sus dispositivos. Es la praxis del texto, que no la instancia narradora, la que nos revela su genealogía. El Nouveau Roman conjuraba el realismo sociológico balzaciano por sus personajes sobredeterminados psicológica y socialmente, su ilusión referencial, su intriga causalista y cronológica (Wagner 2011). Del mismo modo, Sánchez Ferlosio, García Hortelano, Goytisolo y, en menor medida, Cela, se distanciaron de un realismo-copia convencional criticando las novelas de aventura y sentimentales, invitando a romper sus automatismos representativos para "decondicionar" la visión del mundo del lector (Champeau 1993: 370-371, 382). Resulta contundente el paralelismo con la intención narrativa llevada a cabo en El vano ayer. En términos de Schaeffer (1989), desde la recepción podemos dibujar así una continuidad analógica (relación de parecido con otras obras) y tal vez genealógica (relación de herencia respecto a otros textos o corrientes) entre El vano ayer y las novelas identificadas por Geneviève Champeau como de "objetivismo" exacerbado de los años 1950 en España. Estas son, en cierto modo y a partir de los años 60, precursoras del trabajo de escritores como Martín-Santos o Goytisolo. Resulta que Isaac Rosa los cita como modelos literarios (Corsario de Hierro 2004: s/p), lo que sitúa la continuidad genealógica con estos dos autores en el plano auctorial.

Ahora bien, la empresa de categorización de obras por criterio genealógico se desenvuelve en el terreno de la ideología, puesto que abarca aquí la compleja y polémica recepción de la generación del compromiso político de los años 1950 (Champeau 2001: 208). A este nivel también, el del complejo teatro de la institución literaria y su red de discursos y poderes, se plantea el problema 
de la representatividad, de la enunciación y de la legitimidad literaria y política que ya hemos abordado. En este sentido, El vano ayer reintegra y parodia esta esfera mediante un dispositivo enunciativo teatral: la intervención de lectores y de críticos que dictan juicios de valor y prescripciones a propósito de la novela (Rosa 2004: 14, 81, 137, 189, 191). El realismo, además de una constante de representación o de una opción estética construida con una comunidad de lectores, es una categoría de la crítica que genera dinámicas de apropiación. Con esta perspectiva, el gesto de renovación del realismo propuesto por la metáfora del teatro en El vano ayer cobra un sentido ideológico suplementario. Nos limitaremos a señalar dos movimientos inversos de discursos de posicionamiento que ayudan a situar sus coordenadas dentro de la institución literaria.

Por una parte, se ha destacado ya (Champeau 1993) el poder de paradigma dominante del realismo como primacía del contenido social a mediados del siglo xx. Ocultó por ejemplo la labor novedosa de un grupo de autores objetivistas que hemos citado anteriormente y que la crítica sumergió en el conjunto de la "novela social" sin advertir su especificidad. Por otra, al contrario, hoy la generación de los 50 y 60 padece una severa recepción crítica, a la vez que el canon tradicional decimonónico sufre cierto descrédito (Sanz Villanueva 2011). Rosa, y con él varios autores y críticos de perspectiva marxista o neomarxista, identifican en las letras españolas contemporáneas el lugar privilegiado que ocuparía un formalismo de corte posmodernista como el de los Nocilla. Un paradigma crítico que vendría heredado del posmodernismo, establecido como norma cultural de la Transición que rechazaría lo político fuera de la esfera literaria.

En este contexto, enunciar en entrevistas, como lo emprende Rosa, el ostracismo que padece el realismo social de mediados de siglo (Riaño 2011a) y deplorar cierta lectura generalizada de La colmena (Corominas 2007), cobra un significado específico. Asimismo, procurar huir de la etiqueta "experimentalismo" y reivindicar dentro de la misma entrevista la herencia de Martín-Santos o Goytisolo (Corsario De Hierro 2004), que la crítica tiende a categorizar como experimentalistas, provoca especulaciones a la hora de clasificar estética e ideológicamente la obra de su autor. La reescritura del pasado reciente en la literatura, que funda una renovación del realismo, abarca dinámicas de apropiación en el campo literario que no dejan de ser opciones ideológicas. ¿En qué medida la categoría de "nuevos realismos" surgida entre la crítica, las abarca, distingue o trasciende?

\section{CONCLUSIÓN}

En El vano ayer, la teatralidad no aparece tan estructurante como en La mano invisible, en el sentido que le da Geneviève Champeau (2014). Se trata ante todo de invasión del léxico y del espacio poético: la metáfora del teatro, cuando se despliega en el discurso metanarrativo, designa explícitamente múl-

\footnotetext{
9 Declara Rosa al periodista, sobre su obra: "No es una escritura convencional, pero tampoco es experimental. Recurre a múltiples recursos y técnicas, pero intentando que no se conviertan en fuegos artificiales" (Corsario de Hierro 2004: s/p).
} 
tiples fallos en el tratamiento ficcional del pasado en la novela de la memoria. En La mano invisible, el papel crítico lo cumple mucho menos un locuaz autor diegético que un dispositivo, una estructura global de la obra. Pero hemos visto que la metáfora cobra una gran eficacia por su poética. Sus desplazamientos en el espacio del texto esbozan un mapa de uso de los tópicos y las mentiras del régimen franquista, cuya ostentosa pervivencia viene subrayada en la sociedad contemporánea. El procedimiento y la connotación más problemática de la metáfora estriban en el gesto de asimilación entre distintas corrientes realistas caricaturizadas. Sin embargo, cobra sentido cuando lo vinculamos con la necesidad que formula El vano ayer de ejemplificar la presencia del melodrama como trama de fondo de la narrativa actual de éxito. Este infratexto implícito sella el vínculo estético, genealógico entre la novela de la memoria, el realismo tradicional y el contemporáneo. Así toma posición la novela en el debate sobre la noción de representación por el lenguaje, y de mímesis literaria. Se revela la metáfora de la teatralidad como estrategia para plantear un vínculo estrecho entre representación/representatividad literaria y representación/representatividad política que dibuja un hilo de preocupaciones comunes muy estrecho con La mano invisible. La última vuelta de tuerca de la metáfora del teatro lleva entonces a Rosa a representar (aunque de manera más tenue) el campo de poderes de la literatura como institución. Esto nos llevó a considerar lo que tiene de ideológico, en primera o última instancia, el posicionamiento en la esfera del arte, y a examinar brevemente cómo se situaba la obra de Rosa, no sin contradicciones entre el decir del autor y el hacer en el texto, para ahondar en otro(s) sentido(s) de la categoría de los "nuevos realismos".

Por fin, recordemos que en el panorama de los nuevos derroteros del realismo, se identifica a Rosa como representante de un realismo reflexivo y exigente. Esta tendencia o subcategoría exige ciertas precauciones, ya que la dinámica de deconstrucción sistemática de El vano ayer, propia de este realismo crítico, tiende a desbocarse. La instancia narrativa se mofa de varios procedimientos literarios (perspectivismo, polifonía, hibridez formal) no por su falta de calidad literaria sino por su mero éxito en la producción contemporánea. Es como si cualquier herramienta literaria fuera ya tópica. Además, rechaza, tal vez como posición límite, una de las prerrogativas de la novela: el pathos. Ahora bien, este recurso resulta decisivo en el patrón melodramático muy apreciado por los lectores. Bien es cierto que varios indicios, en el relato, invitan a desconfiar de su enunciador omnipotente. Sin embargo, ¿qué implica el encumbrar en la escala del valor literario una obra que vilipendia uno de los recursos que bien podría respaldar la relación del público con el género novelesco? La vuelta del realismo invitaría a matizar el cruce complejo entre definición del valor literario y aprecio del público. 


\section{OBRAS CITADAS}

Bértolo, Constantino (2007a): "Realidad, comunicación y ficción. A propósito de El padre de Blancanieves". En: Matías Escalera Cordero (ed.): La (re)conquista de la realidad: la novela, la poesía y el teatro del siglo presente. Madrid, Tierradenadie, pp. 129-146. (2007b): "La narrativa de los realismos". En: El realismo social en la literatura española: homenaje a Juan García Hortelano. Málaga, Fundación Domingo Malagón, Centro de Ediciones de la Diputación de Málaga, pp. 13-19.

Bonvalot, Anne-Laure (2010): "Entre la espada y la pared: nouvelles écritures engagées dans le roman espagnol contemporain (Belén Gopegui, Isaac Rosa)". En: Langues néo-latines: Revue des langues vivantes romanes, n. ${ }^{\circ} 354$, pp. 25-44.

Carcelén, Jean-François (2011): "Ficción documentada y ficción documental en la narrativa española actual: Ignacio Martínez de Pisón, Isaac Rosa". En: Geneviève Champeau et al. (eds.): Nuevos derroteros de la narrativa española actual: veinte años de creación. Zaragoza, Prensas Universitarias de Zaragoza, pp. 51-68.

Chamouleau, Brice (2011): "L'affaire Jeremy Thorpe: I'homosexualité en Espagne et le miroir britannique dans la transition à la démocratie". En: M. C. Chaput (ed.): Masculin/ Féminin dans la transition espagnole. Regards, n. ${ }^{\circ}$ 17, pp. 185-199.

Champeau, Geneviève (1993): Les enjeux du réalisme dans le roman sous le franquisme. Madrid, Casa de Velázquez.

(2001): "Recepción de la novela realista de posguerra". En: Paul Aubert (ed.): La novela en España (siglos xIx y xx). Actas del coloquio internacional celebrado en la Casa de Velázquez (17-19 de abril de 1995). Madrid, Casa de Velázquez, pp. 207-219. (2014): "Realismo y teatralidad: de Benito Pérez Galdós a Isaac Rosa". En: Pasavento. Revista de Estudios Hispánicos, n. 3, pp. 11-32.

Chartier, Roger (2002): "La construcción estética de la realidad. Vagabundos y pícaros en la Edad Moderna". En: Tiempos Modernos, vol. 3, n. 7 . Disponible en <http://www. tiemposmodernos.org/tm3/index.php/tm/article/viewFile/20/39>. Última consulta: 11.09.2013.

Chirbes, Rafael (2000): La caída de Madrid, Madrid, Anagrama.

Colmeiro, José (2005): Memoria histórica e identidad cultural. De la postguerra a la postmodernidad. Barcelona, Anthropos.

Compagnon, Antoine (2001): "Poétique des genres: Aristote". En: <http://www.fabula.org/ compagnon/genre4.php>. Última consulta: 30.08.2013.

Corominas, David (2007): "Entrevista con el escritor Isaac Rosa. «Una visión nostálgica es también una visión política»". En: <https://www.diagonalperiodico.net/culturas/ vision-nostalgica-es-tambien-vision-politica.html>. Última consulta: 11.09.2013.

Corsario de Hierro (2004): "Entrevista a Isaac Rosa para Anika Entre Libros". En: <http:// libros2.ciberanika.com/desktopdefault.aspx?pagina= /paginas/entrevistas/ entre53.ascx>. Última consulta: 11.09.2013.

Dufour, Philippe (1998): Le Réalisme. París, Presses Universitaires de France.

Escaleras Cordero, Matías (2007): "El vacío abisal de una literatura sin realidad presente (ni pasada)". En: Matías Escalera Cordero (ed.): La (re)conquista de la realidad: la novela, la poesía y el teatro del siglo presente. Madrid, Tierradenadie, pp. 7-16. 
Florenchie, Amélie (2011): "Isaac Rosa o la 'escritura responsable'". En: Amélie Florenchie e Isabelle Touton (eds.): La ejemplaridad en la narrativa española contemporánea (1950-2010). Madrid/Frankfurt, Iberoamericana/Vervuert, pp. 131-149.

Garcés, Joan (1996): Soberanos e intervenidos: estrategias globales, americanos y españoles. Madrid, Siglo xxl.

Gefen, Alexandre (ed.) (2003): La mimèsis. París, GF Flammarion.

Gopegui, Belén (2008): Un pistoletazo en medio de un concierto: acerca de escribir de política en una novela. Madrid, Editorial Complutense.

Hansen, Hans Lauge (2011): "Multiperspectivism in the Novels of the Spanish Civil War". En: Orbis Litterarum n. ${ }^{\circ} 66$, vol. 2, pp. 148-166.

Labanyi, Jo (2007): "Memory and Modernity in democratic Spain: The Difficulty of Coming to Terms with the Spanish Civil War". En: Poetics Today, vol. 28, n. ${ }^{\circ} 1$, pp. 89-116.

Labrador Méndez, Germán (2011): "Historia y decoro. Éticas de la forma en las narrativas de memoria histórica". En: María del Palmar Álvarez Blanco y Antonio Dorca (eds.): Contornos de la narrativa española actual (2000-2010): un diálogo entre creadores y críticos, Historia y decoro. Madrid/Frankfurt, Iberoamericana/Vervuert, pp. 121-130. (2012): "Las vidas subprime: la circulación de historias de vida como tecnología de imaginación política en la crisis española (2007-2012)". En: Hispanic review, n. ${ }^{\circ} 4$, pp. 557-581.

Martínez, Guillem (ed.) (2012): CT o la Cultura de la Transición. Crítica a 35 años de cultura española. Barcelona, Debolsillo.

Martínez Rubio, José (2013): "'La cultura española no ha estado a la altura de la sociedad civil'. Entrevista a Isaac Rosa". En: Kamchatka, n. ${ }^{\circ}$ 1, pp. 261-266.

Merino, Eloy E. (2007): "Reescritura, melodrama y modernización en Alceste, de B. P. Galdós (eco en las últimas heroínas dramáticas del escritor)". En: Decimonónica, vol. 4, n. 1, pp. 52-79.

Orsini-Saillet, Catherine (2010): "Regards sur la Transition dans le roman espagnol actuel: La caída de Madrid de Rafael Chirbes et Romanticismo de Manuel Longares". En: Les langues Néo-latines, n. 354, pp. 65-88.

Rancière, Jacques (2000): Le partage du sensible. París, La Fabrique.

Riaño H., Peio (2011a): "La novela política entre las palabras y las ideas". En: <http://www. publico.es/culturas/365761/la-novela-politica-entre-las-palabras-y-las-ideas>. Última consulta: 11.09.2013.

(2011b): "Entrevista a Isaac Rosa: «En la novela española actual se trabaja poco»". En: <http://www.publico.es/393195/en-la-novela-espanola-actual-se-trabaja-poco>. Última consulta: 11.09.2013.

Ricardou, Jean (1970): "Nouveau Roman, Tel Quel". En: Poétique, n. ${ }^{4}$, pp. 433-454.

Ríos-Font, Wadda C. (1997): Rewriting melodrama. The hidden paradigm in Modern Spanish theater. Lewisburg/Londres, Bucknell University Press, Associated University Presses.

Rosa, Isaac (2004): El vano ayer. Barcelona, Seix Barral.

(2011): La mano invisible. Barcelona, Seix Barral.

Riffaterre, Michael (1970): "Le poème comme représentation". En: Poétique, n. 4, pp. 401418. 
_ (1982): "L'illusion référentielle" [1978]. En: Gérard Genette y Tzvetan Todorov (eds.): Littérature et réalité. París, Seuil, pp. 91-118.

Rubio, Isaac (1981): "Galdós y el melodrama". En: Anales galdosianos, año xvı, pp. 57-68.

Sánchez León, Pablo, e Izquierdo Martín, Jesús (2006): La guerra que nos han contado: 1936 y nosotros. Madrid, Alianza.

Sanz, Marta (2001): Los mejores tiempos. Madrid, Debate.

Sanz Villanueva (1985): "El realismo en la nueva novela española". En: Ínsula, n. $464-465$, p. 7.

(2009): "Isaac Rosa o la reinvención del realismo social". En: Cuadernos hispanoamericanos, n. ${ }^{\circ}$ 703, pp. 87-94.

Schaeffer, Jean-Marie (1989): Qu'est-ce qu'un genre littéraire? París, Seuil.

Sobejano, Gonzalo (1976): "Echegaray, Galdós y el melodrama". En: Anales Galdosianos. Anejo, pp. 91-117.

(2003): "Narrativa española 1950-2000: la novela, los géneros y las generaciones". En: Luis Goytisolo (ed.): Panorama de la literatura contemporánea. Arbor, n. ${ }^{\circ}$ 693, pp. 99-114.

Todorov, Tzvetan (1982): "Présentation". En: Gérard Genette y Tzvetan Todorov (eds.): Littérature et réalité. París, Seuil, pp. 8-10.

Tyras, Georges (2011): "Relato de investigación y novela de la memoria: Soldados de Salamina de Javier Cercas y Mala gente que camina de Benjamín Prado". En: Geneviève Champeau et al. (eds.): Nuevos derroteros de la narrativa española actual: veinte años de creación. Zaragoza, Prensas Universitarias de Zaragoza, pp. 343-364.

VV.AA. (2013): "El fin de la España de la Transición. Las lagunas democráticas, el desplome económico y la corrupción noquean el orden de 1978". Cuadernos, n. ${ }^{\circ} 1$.

Villanueva, Darío (1992): Teorías del realismo literario. Madrid, Instituto de España.

Wagner, Frank (2011): "Raconter est-il devenu proprement impossible? Fabula et intrigue dans I'œuvre romanesque d'Alain Robbe-Grillet". En: <http://www.fabula.org/ atelier.php?Fabula_et_intrigue>. Última consulta 05.09.2013. 